\title{
PESQUISA-FORMAÇÃO DE PROFESSORES NAS DISSERTAÇÕES, TESES: 1999-2008*
}

\author{
Luis Eduardo Alvarado Prada** \\ Andréa Maturano Longarezi ${ }^{* * *}$
}

Resumo: O objetivo geral da pesquisa foi "conceituar pesquisa-formação, com vistas a contribuir para a construção de um campo conceitual-prático da pesquisa e da formação de professores e para a construção de uma epistemologia da formação docente". Neste texto se faz um recorte desse objetivo para mapear as denominações dadas pelos autores das dissertações e teses dos Programas de Pós-graduação em Educação das Universidades Brasileiras (período 1999-2008) às modalidades de pesquisa e ou metodologias realizadas mediante pesquisas de intervenção para formação de professores. Foram encontradas 7.390 dissertações e/ou teses. Mediante análise dos títulos, as palavras chave e os resumos, foram identificadas 1.353 pesquisas sobre formação de professores. Dessas, 177 foram identificadas como pesquisa intervenção para a formação de professores, nas quais resultaram mais de 40 denominações de tipos e/ou metodologias de pesquisa. Também resultou uma listagem de autores que fundamentaram os tipos de pesquisa ou metodologias utilizadas pelos autores dos trabalhos de dissertações e teses. Esses resultados mostram um reduzido número de pesquisas de intervenção no país e a hegemonia de certas concepções tradicionais, a maioria fundamentada em autores estrangeiros.

Palavras-chave: Pesquisa-formação. Metodologias de pesquisa. Pósgraduação educação. Professores. 
Abstract: The main objective of this research was "to conceptualize research-formation, with views to contribute for a construction of a conceptual-pragmatical research field and formation of teachers, and for the construction of a teacher formation epistemology". The article presents a clipping of this objective, in order to scan the denominations given by the authors of dissertations and thesis of educational post-graduate programs from Brazilian Universities (1999-2008), the modalities of research and/ or methodologies performed using intervention researches for formation of teachers. 7390 dissertations and/or thesis were found. By analyzing titles, keywords, and abstracts 1353 researches about formation of teachers were identified. Of these, 177 were identified as intervention research for formation of teachers, in which more than 40 denominations were about types and/or research methodologies. Also, resulted a list of authors that substantiate the types of research or methodologies used by the authors of the dissertations and thesis works. These results show a reduced number of intervention researches in the country and the hegemony of certain traditional conceptions, most of these based on foreign authors.

Keywords: Research-formation. Research methodology. Postgraduate formation. Teachers. 
Os processos de formação desencadeados pela pesquisa “[...] tendem a alimentar a consciência crítica, o questionamento, a capacidade de intervenção e a consolidar a unidade teoria-prática.” (LONGAREZI; SILVA, 2010a, p. 3).

A formação de professores tem sido objeto de inúmeros estudos, pesquisas e intervenções realizadas no âmbito educacional. A crescente demanda pela investigação nesse campo coloca em foco dois aspectos às vezes antagônicos. Se por um lado, ao professor é atribuído o papel de promotor e transmissor da cultura, formador de opiniões e gerador de desenvolvimento humano, tecnológico e social, o que confere a ele uma posição de destaque no concernente à construção do espírito crítico da sociedade; por outro, ele é responsabilizado pela situação da educação quando os problemas e dificuldades presentes no atual sistema de ensino são entendidos como decorrentes da má atuação docente.

Frente à complexidade dessas questões, com seus paradoxos, a formação de professores assume contornos de um verdadeiro desafio para os pesquisadores, formadores de professores e para os elaboradores e executores das políticas públicas de formação.

Em muitas circunstâncias se têm buscado a formação pela pesquisa, entendida como potencializadora de processos formativos conscientizadores e desalienantes (LONGAREZI; SILVA, 2010a). A crescente busca por abordagens dessa natureza tem se firmado por diferentes metodologias: pesquisa-ação (THIOLLENT, 1987a, 1987b, 1997, 1998; BARBIER, 2004), colaborativa (IBIAPINA, 2008; GARRIDO; PIMENTA; MOURA, 2000; MOURA; FERREIRA, 2004; MARIN et al., 2000), participante (FALS BORDA, 1978, 1981, 1990; FREIRE, 1968, 1974, 1978, 1981a, 1981b, 2007a, 2007b, 2007c; BRANDÃO, 1990; BOTERF, 1987; GAJARDO, 1987; EZPELETA, 1989), coletiva (ALVARADO PRADA, 1997, 
2005, 2006a, 2006b, 2008, 2010), trabalho metodológico (HORRUITINER, 1979, 1998, 2006); supervisão e formação interpares (NÓVOA, 2000); supervisão clínica (GARCÍA, 1999); formação centrada na escola e no curso (IMBERNÓN, 2002); entre outras.

A inserção da pesquisa no âmbito do trabalho do professor tem sido marcada por obstáculos ou desafios, dentre eles destacam-se: a pertinência do tipo de pesquisa desenvolvida, a disposição e interesse dos professores em participar do processo formativo, a disponibilidade de instalações apropriadas, as necessidades da escola e dos participantes, a privacidade das práticas pedagógicas, a autonomia exagerada dos professores em detrimento de uma autonomia colegiada e a fragilidade dos mecanismos institucionais (cf. PUENTES; AQUINO, 2010).

A ideia do professor como pesquisador surgiu há décadas e desde então vem sendo alvo de estudos e reformulações, principalmente, pelas universidades que desenvolvem ou pretendem realizar um trabalho conjunto com os professores das redes de ensino fundamental e médio. Assim sendo, não são quaisquer tipos de pesquisa que podem ser empregados com a finalidade de promover formação, somente aqueles que possibilitem uma participação efetiva dos professores na concepção e realização das atividades previstas, que apresentem uma flexibilidade em relação ao conteúdo investigado e cuja finalidade priorize muito mais a formação do que a mera coleta de dados.

Nessa perspectiva, a formação continuada precisaria: 1) privilegiar situações a partir das quais os próprios educadores desenvolvessem e produzissem práticas e saberes novos, articulados com as teorias educacionais, mediante processos de investigação e colaboração em seus espaços de trabalho; 2) ter como objeto de estudo as demandas da instituição, as necessidades e interesses 
formativos dos professores e as necessidades de aprendizagens dos estudantes.

Diante dessas situações, foi desenvolvido o projeto Pesquisa e formação de professores: contribuições para a construção de um campo conceitual-prático da pesquisa-formação, procurando analisar, no âmbito das pesquisas de intervenção que propuseram processos de formação de professores, a dimensão formativa de tais pesquisas, bem como a natureza investigativa desses processos formativos. Também se procura levantar aspectos relacionados com essas intervenções que contribuam para a construção de um campo conceitual-prático da pesquisa-formação.

Considerou-se como sendo pesquisa de intervenção sobre/com professores todos os trabalhos que propuseram estratégias junto a um ou mais professores com o intuito explícito de desencadear algum processo e formação de professores. Com esse entendimento procurou-se, nos enunciados sobre a metodologia utilizada e os objetivos propostos nas dissertações e teses, identificar em quais dessas pesquisas havia ocorrido algum tipo de intervenção, com o intuito de promover formação junto aos professores. Essa identificação, em alguns casos, foi possível, com a leitura apenas dos títulos, resumos e palavras-chave; em outros, foi preciso a consulta ao capítulo metodológico ou o trabalho na íntegra.

Dessa forma, foram levantadas, junto aos sites dos programas de pós-graduação em educação e da ANPED, todas as teses e dissertações defendidas, no período, em 30 universidades públicas e privadas, distribuídas nas cinco regiões do Brasil, no período de 10 anos (1999 a 2008), totalizando um número de 7.390 trabalhos de pesquisa desenvolvidos e defendidos nesses programas, distribuídos pelas cinco regiões brasileiras. Assim, levantado o volume de pesquisa discente no interior dos programas, procedeu-se a identi- 
ficação. Isso ocorreu mediante a localização da expressão "formação de professores" nos títulos, resumos e/ou palavras-chave dos trabalhos. Do total de 7.390 pesquisas, 1.159 ou (15,68\%) foram sobre formação de professores. No GT8 formação de professores da ANPED foram apresentados 113 trabalhos. Desse modo, foram identificadas 160 teses e dissertações de formação com intervenção nas cinco regiões do Brasil e 17 trabalhos dos apresentados no GT8 da ANPED. O relacionado com o estudo desses 17 trabalhos não é apresentado neste texto.

Para a análise das concepções de pesquisa enunciadas nas dissertações e teses foram selecionadas somente aquelas disponíveis na íntegra virtualmente. Isso para, quando necessário, poder ler o trabalho completo. Assim, resultaram 104 de um total de 160 trabalhos de formação com intervenção. Foram analisados 76 trabalhos da região Sudeste, 9 trabalhos da região Centro-Oeste e 9 da região Sul, nenhum trabalho na região Norte e 10 trabalhos na região Nordeste.

\section{Metodologia de pesquisa enunciadas nas dissertações e teses}

O estudo dos processos de pesquisa de/sobre formação de professores com intervenção, nas teses e dissertações defendidas no Brasil durante o período 1999-2008, permitiu fazer um levantamento das denominações dadas por seus autores às metodologias utilizadas. Essas denominações se apresentam na tabela a seguir. 
Tabela 1 - Denominações de metodologia registradas nos trabalhos das cinco regiões

\begin{tabular}{|l|c|c|}
\hline \multicolumn{1}{|c|}{ Denominação da metodologia } & No & $\%$ \\
\hline Trabalhos sem denominação & 48 & 25,80 \\
\hline Pesquisa-ação & 44 & 23,65 \\
\hline Pesquisa qualitativa & 22 & 11,82 \\
\hline Estudo de caso & 12 & 6,45 \\
\hline Pesquisa colaborativa & 8 & 4,30 \\
\hline Pesquisa etnográfica & 4 & 2,15 \\
\hline Pesquisa-ação colaborativa & 4 & 2,15 \\
\hline Pesquisa participante & 4 & 2,15 \\
\hline Pesquisa coletiva & 2 & 1,07 \\
\hline Estudo de caso etnográfico & 2 & 1,07 \\
\hline Pesquisa intervenção, segundo um modelo colaborativo-construtivo & 2 & 1,07 \\
\hline Pesquisa construtivo-colaborativa & 2 & 1,07 \\
\hline Trabalho colaborativo & 2 & 1,07 \\
\hline Pesquisa interpretativa & 2 & 1,07 \\
\hline Pesquisa-ação na perspectiva colaborativa & 1 & 0,53 \\
\hline Pesquisa-formação & 1 & 0,53 \\
\hline Etnopesquisa-formação & 1 & 0,53 \\
\hline Pesquisa qualitativa com abordagem sócio-histórica & 1 & 0,53 \\
\hline Investigação-ação educacional & 1 & 0,53 \\
\hline Pesquisa descritivo-analítica & 1 & 0,53 \\
\hline Pesquisa associada ao modelo construtivo-colaborativo de intervenção & 1 & 0,53 \\
\hline Pesquisa etnográfica colaborativa & 1 & 0,53 \\
\hline Investigação ação-escolar & 1 & 0,53 \\
\hline Pesquisa intervenção colaborativa & 1 & 0,53 \\
\hline Pesquisa cooperativa & 1 & 0,53 \\
\hline Estudo de caso do tipo observacional & 1 & 0,53 \\
\hline Pesquisa participativa & 1 & 0,53 \\
\hline Pesquisa-ação participativa & 1 & 0,53 \\
\hline Pesquisa qualitativa com características de pesquisa participante & 1 & 0,53 \\
\hline Pesquisa qualitativa de caráter etnográfico & 1 & 0,53 \\
\hline Pesquisa intervenção & 1 & 0,53 \\
\hline Pesquisa narrativa com oportunidade de ação-reflexão-ação & 1 & 0,53 \\
\hline Pesquisa investigação-formação & 1 & 0,53 \\
\hline Método dialético & 1 & 0,53 \\
\hline Metodologia da equivalência de estímulos & 1 & 0,53 \\
\hline Investigação descritiva & 1 & 0,53 \\
\hline
\end{tabular}




\begin{tabular}{|l|l|l|}
\hline Método clínico ou crítico de Jean Piaget & 1 & 0,53 \\
\hline Pesquisa de campo de natureza exploratória & 1 & 0,53 \\
\hline Pesquisa alteridade-formação & 1 & 0,53 \\
\hline Pesquisa-ação participante & 1 & 0,53 \\
\hline Metodologia de tomada de dados & 1 & 0,53 \\
\hline Investigação-ação & 1 & 0,53 \\
\hline TOTAL & $\mathbf{1 8 6}$ & $\mathbf{1 0 0}$ \\
\hline
\end{tabular}

Fonte: elaboração dos autores.

No processo da pesquisa, foi analisada cada uma dessas denominações e elaborado um resumo do qual se faz, para este trabalho, uma síntese enunciando alguns de seus fundamentos e autores dos mesmos. A tabela a seguir visualiza a lista desses autores.

Tabela 2 - Autores referenciados para a metodologia nos trabalhos das cinco regiões

\begin{tabular}{|l|c|c|}
\hline \multicolumn{1}{|c|}{ Autores (metodologia) } & No & $\mathbf{\%}$ \\
\hline Autores citados apenas 1 vez & 49 & 29,69 \\
\hline Thiollent (1988, 1992, 1994, 1998, 2000, 2001, 2002, 2003, 2004, 2005) & 24 & 14,54 \\
\hline Ludke e André (1986, 2004) & 12 & 7,27 \\
\hline Bodgan e Biklen (1982, 1991, 1994) & 10 & 6,06 \\
\hline Barbier (2002, 2004) & 9 & 5,45 \\
\hline André (1986, 1995, 2000, 2001, 2003) & 8 & 4,84 \\
\hline Não cita autores de metodologia & 7 & 4,24 \\
\hline Freitas (2002) & 5 & 3,03 \\
\hline Pereira (2001, 2002) & 5 & 3,03 \\
\hline Trivinõs (1987, 1995) & 4 & 2,42 \\
\hline Cole e Knowles (1993) & 3 & 1,81 \\
\hline Kemmis \& Wilkinson (2002) & 3 & 1,81 \\
\hline Macedo (2000, 2006) & 3 & 1,81 \\
\hline Carr e Kemmis (1998) & 3 & 1,81 \\
\hline Alvarado Prada (2006, 1997) & 2 & 1,21 \\
\hline Chizzotti & 2 & 1,21 \\
\hline Demo (1987, 2004) & 2 & 1,21 \\
\hline Fals Borda (1981) & 2 & 1,21 \\
\hline Kemmis (1986, 1987) & 2 & 1,21 \\
\hline
\end{tabular}




\begin{tabular}{|l|c|c|}
\hline Magalhes (1994) & 2 & 1,21 \\
\hline Minayo (2001) & 2 & 1,21 \\
\hline Morin (1998) & 2 & 1,21 \\
\hline Ponte (2005) & 2 & 1,21 \\
\hline Kemmis e MCTaggart (1988) & 2 & 1,21 \\
\hline TOTAL & $\mathbf{1 6 5}$ & $\mathbf{1 0 0}$ \\
\hline
\end{tabular}

Fonte: elaboração dos autores.

Esses tipos de pesquisa são apresentados a seguir com o intuito de ter uma ideia do que os autores dos trabalhos apresentaram. Entretanto, é uma síntese dos textos que, em alguns casos, constituíram quase um capítulo da dissertação ou tese; em outros casos a denominação foi só uma frase, mas dentro da descrição dos procedimentos conseguimos resgatar informações para esta síntese que apresentamos a seguir.

\section{Pesquisa-ação}

Em muitos trabalhos a pesquisa-ação foi definida de acordo com a perspectiva de (THIOLLENT, 2001, 2007) como um tipo de pesquisa social com base empírica que é concebida e realizada em estreita associação com uma ação ou com a resolução de um problema coletivo em que os pesquisadores e os participantes estão envolvidos de modo cooperativo ou participativo.

De acordo com Fiorentini (2004), nessa metodologia de intervenção caminham juntas a prática investigativa, a prática reflexiva e a prática educativa. De acordo com Barbier (2002), outro autor citado, a pesquisa-ação tem um papel tanto social como pedagógico e político. 
Essa metodologia foi caracterizada pelo papel ativo dos pesquisadores junto aos sujeitos da pesquisa. Nas coletas de dados predominaram as entrevistas, questionários, análise documental e observação participante. A realização de reuniões, cursos, grupos de estudos e encontros de formação continuada de professores fizeram parte das intervenções e do apoio oferecido aos professores.

Um trabalho apresenta a ideia de que a atividade formativa (realizada em forma de reuniões) foi elaborada de acordo com uma pauta previamente definida pelo pesquisador junto ao grupo de professores. Essa pauta se refere às necessidades formativas do grupo em contexto.

Em dois trabalhos a pesquisa-ação foi utilizada seguindo o processo definido por André (1995) com o emprego cíclico de atividades de análise, obtenção de dados, identificação dos possíveis problemas, planejamento da ação, execução e nova obtenção de dados. Outro autor referenciado nos trabalhos é Pereira (1998). Para esse autor, a pesquisa-ação é um “[...] meio de produzir conhecimento sobre os problemas vividos pelo profissional, com vista a atingir uma melhora da situação, de si mesmo e da coletividade."

Nessa metodologia, segundo os trabalhos analisados, a pesquisa-ação induz ao questionamento, à busca, ao papel ativo dos professores participantes, à reflexão sobre suas práticas para posteriormente reconstruí-las, permitindo, assim, a apropriação partilhada do conhecimento. 


\section{Pesquisa colaborativa}

Os trabalhos se fundamentaram em vários autores para conceituar pesquisa colaborativa, tais como Zeichner (1993), Fiorentini (2004), Candau (1996) entre outros.

Na pesquisa colaborativa, pressupõe-se a efetivação da mudança numa ação de parceria entre professores e pesquisadores. Um dos autores se fundamentou em Zeichner (1993) entendendo que a pesquisa colaborativa tem por objetivo criar nas escolas uma cultura de reflexão das práticas para a transformação dessas práticas e das ações institucionais. Outro autor se fundamenta em Kemmis (1987), entendendo que colaboração significa negociação e tomada de decisão conjunta nas ações do formador-pesquisador que busca refazer as práticas pelas quais interage, sendo, simultaneamente, investigador e objeto de investigação de sua própria prática.

Desgagné (2003), citado em um trabalho, assinala que “[...] a pesquisa colaborativa proporciona aos docentes a tomada de poder de sua prática reflexiva, compartilhada entre eles e o pesquisador." Também, Fiorentini (2004) é referenciado apontando algumas características do trabalho colaborativo: participação voluntária, socialização de saberes, definição de tarefas e tomada de decisão por todo o grupo.

\section{Estudo de caso}

É apresentado como aquele que possibilita descrever analiticamente e intensamente o objeto estudado (YIN, 1989). Nessa metodologia se enfatiza o conhecimento particular. Algumas caracterís- 
ticas básicas são apontadas por Ludke e André (2004): visa à descoberta, o pesquisador deve estar atento para os novos elementos que podem surgir, enfatiza a interpretação, busca retratar a realidade, usa variadas fontes de informações e permite generalizações.

\section{Pesquisa qualitativa}

A maioria dos trabalhos cita Bogdan e Biklen (1994) como referência para defini-la por entender que nessa metodologia o pesquisador é o principal instrumento da investigação, é feita uma investigação de caráter descritivo e os dados são analisados de forma indutiva a partir do agrupamento dos dados particulares.

Nesses trabalhos, após a coleta de dados mediante observações, entrevistas e/ou questionários, a intervenção foi desenvolvida através da realização de cursos de formação para os professores, encontros com os professores, criação de grupos de discussão/reflexão, realização de oficinas e minicursos desenvolvidos, em sua maioria, no Horário de Trabalho Pedagógico Coletivo (HTPC).

\section{Construtivo-colaborativa}

A metodologia construtivo-colaborativa foi utilizada porque, segundo os pesquisadores, valoriza a prática do professor como eixo central de análise, partindo dessa prática para discutir os problemas, desenvolver novos conhecimentos e elaborar possíveis soluções (LUCARELI apud REALI et al., 1995). Além disso, segundo Cole e Knowles (1993), referenciados nos trabalhos, essa metodologia possibilita que os envolvidos, professores e pesquisa- 
dores, assumam papéis de natureza colaborativa, aprendendo um com o outro.

Todos os trabalhos utilizaram entrevistas, questionários e/ou diários reflexivos para coletar os dados sobre a formação e as necessidades dos professores envolvidos.

\section{Investigação-ação}

Nesse tipo ou método (de acordo com alguns autores) de investigação permite fazer questionamentos sobre a prática educativa e os interesses de estudo estão mais nos problemas práticos do cotidiano do que em problemas técnicos.

Kurt Lewim é referenciado pelo entendimento de que "[...] a investigação-ação é uma espiral de passos que se compõem de um ciclo de planificação, ação e produtos acerca dos resultados da ação." (GARCIA, 1999, p. 182).

Outro pesquisador referencia Thiollent (2004), entendendo que "[...] a investigação-ação visa a emancipação dos seres humanos e a transformação da realidade a partir da interpretação da prática, das concepções e dos valores das colaboradoras.” Acrescenta ainda, segundo o mesmo autor, que na investigação-ação o pesquisador intervêm de modo intencional e os participantes são colaboradores em ação, com papel ativo no processo.

\section{Pesquisa participante/participativa}

Nos trabalhos é enunciado que, na pesquisa participante, os sujeitos participam junto com os pesquisadores, possibilitando 
o entendimento da realidade educacional de modo mais crítico (EZPELETA; ROCKWELL, 1989). Demo (2004) é referenciado pelo entendimento de que, nessa metodologia, a pesquisa se reveste de valor pedagógico e formativo, na medida em que vê os sujeitos como pensantes e críticos.

Um trabalho que nomeou sua metodologia como pesquisa participativa, escolheu-a por acreditar que os “[...] problemas sociais devem ser refletidos a partir, e de dentro, da sua realidade que é complexa e mutante." (RIZZINII, 1999).

\section{Pesquisa coletiva}

Nos trabalhos, é referenciado Alvarado Prada $(1997,2006)$ entendendo a pesquisa coletiva como sendo uma forma de construção do conhecimento na partilha com o outro, com o objetivo de conhecer e transformar a realidade coletivamente. A pesquisa coletiva, de acordo com esse autor, é entendida como processo que forma pesquisando e pesquisa formando. Desse modo, são valorizados os conhecimentos dos participantes, seu pensar e o agir antes que os universalmente sistematizados.

A pesquisa coletiva foi desenvolvida mediante uma sequência de oficinas, denominadas encontros, nos quais pesquisador e sujeitos da pesquisa levantavam informações sobre os saberes da experiência, interesses e necessidades de cada participante e do coletivo, sistematizavam essas informações e realizavam análises individual e coletivamente, e planejavam atividades para atender situações problemas do coletivo institucional (escolas). Esse processo foi entendido como construção coletiva de conhecimentos. 


\section{Pesquisa intervenção}

Esta pesquisa foi realizada mediante entrevistas individuais e com o desenvolvimento da intervenção (análise e elaboração de casos de ensino pelas professoras, sujeitos da pesquisa). Não foram possíveis encontros coletivos devido à indisponibilidade de horários das professoras. Os casos de ensino tiveram um potencial formativo e investigativo na reflexão das práticas das professoras.

\section{Pesquisa narrativa com oportunidade de comunicação-reflexão}

De acordo com Mont'Alverne Chaves (1999, p. 126-131), essa metodologia possibilita: evocar a experiência humana de forma significativa; tornar o pesquisador mais intimamente ligado ao processo investigativo; favorecer a reflexão sobre os relatos dos sujeitos; dar voz aos sujeitos participantes do estudo; organizar percepção, pensamento, a memória e a ação.

\section{Tomada de dados}

A partir de um levantamento das questões prévias de alunos e professores sobre os elementos da astronomia, a metodologia de tomada de dados foi realizada pela representação de objetos astronômicos pelos professores. Essa representação foi feita com um arranjo experimental e é utilizado na discussão dos movimentos de objetos. 


\section{Investigação-formação}

Nóvoa (apud CANDAU, 1997) entende que a "investigação-formação" abre a possibilidade de inserir a pesquisa em uma perspectiva na qual pesquisador e professores se relacionam mais cooperativamente de forma que ambas as partes ganhem, buscando conceber mudanças na prática docente por meio da reflexão na prática e sobre a prática, valorizando os saberes que as pessoas têm. $\mathrm{O}$ trabalho visou levar os professores a vivenciarem um projeto interdisciplinar utilizando as TIC e a "refletirem na ação, sobre a ação e sobre a reflexão na ação" (SCHON, 2000).

\section{Pesquisa cooperativa}

Fundamentado em Fiorentini (2004), o autor da pesquisa entende que a cooperação é uma fase do trabalho coletivo em que ocorrem ações conjuntas para a execução de tarefas que não resultam de negociação conjunta do grupo.

No trabalho, é utilizada a pesquisa cooperativa professor/pesquisador, entendendo que os professores são protagonistas e responsáveis pela sua própria formação.

\section{Equivalência de estímulos}

Fundamentado em Albuquerque e Melo (2005), um autor de trabalho entende que a metodologia da equivalência envolve o procedimento de discriminação condicional, e em muitos estudos, este é combinado com o procedimento de exclusão. A par- 
tir desses procedimentos, testa-se a emergia de relações de equivalência entre os estímulos. Foi realizada uma coleta inicial dos dados através de entrevistas com intuito de identificar os alunos com dificuldades na leitura de palavras para, então, desenvolver um programa de formação com os professores tendente a aprenderem a manusear um software de computador que seria utilizado posteriormente em sessões com os alunos.

\section{Pesquisa-formação}

O autor do trabalho afirma ter optado “[...] pelo método da pesquisa-formação inspirado nas abordagens da pesquisa-ação em Barbier (2002) e do conceito de formação abordados nos trabalhos de Freire (1998), Macedo (2000, 2001), Nóvoa (1995, 2002 e 2004), e pesquisa-formação em Josso (2004)."

Com base nisso, a pesquisa-formação é definida como sendo uma metodologia que contempla a possibilidade de mudança das práticas, bem como dos sujeitos em formação. Assim, a pessoa é ao mesmo tempo objeto e sujeito da formação (NÓVOA, 2004).

\section{Pesquisa qualitativa e etnográfica}

A pesquisa etnográfica também foi citada como metodologia nos trabalhos da região Nordeste, somente em um trabalho (25\%).

Essa metodologia foi escolhida pelo autor, pois, segundo Ludke e André (1986), ela valoriza a contribuição dos sentidos atribuídos pelos professores no seu processo formativo, bem como seu potencial para estudar questões da escola. A abordagem etnográfica 
da pesquisa em educação diz "[...] ser quase impossível entender o comportamento humano sem tentar entender o quadro referencial dentro do qual os indivíduos interpretam seus pensamentos, sentimentos e ações." (LUDKE; ANDRÉ, 1986).

\section{Etnopesquisa-formação}

Segundo o autor que utilizou esta metodologia, na etnopesquisa-formação o processo ocorre no interior de um problema social, que preocupa o grupo. O pesquisador se implica junto com a coletividade na construção da problemática e as etapas são desenvolvidas em um processo de discussão coletiva (MACEDO, 2000).

A intervenção foi realizada com a formação de Observatórios Etnoformadores (OEF).

\section{Pesquisa-ação na perspectiva colaborativa}

Segundo Lewin, citado por Pereira (2002) essa modalidade de investigação se caracteriza “[...] por seu caráter participativo, o impulso democrático, e sua contribuição tanto para ciência quanto para a transformação da sociedade.”

\section{Estudo de caso do tipo etnográfico}

O pesquisador, em um dos trabalhos, entende que, com essa metodologia de pesquisa, pode-se chegar a uma descrição completa do objeto de estudo e que o trabalho de campo oferece a 
possibilidade de participar ativamente dentro do grupo de sujeitos do estudo. Segundo Ludke e André (1986), a pesquisa etnográfica valoriza a contribuição dos sentidos atribuídos pelos professores no seu processo formativo, bem como seu potencial para estudar questões da escola.

\section{Algumas reflexões sobre esses dados}

As denominações do tipo de pesquisa por seus próprios autores apresentam uma grande dispersão. Das 160 teses e/ou dissertações analisadas, 145 nomearam explicitamente os tipos de pesquisas utilizados em seus trabalhos (ver tabela 1). A nomeação foi tão variada que chegou a 40 denominações diferentes, as quais nem sempre são excludentes e algumas nem se poderiam entender como tipos ou metodologias de pesquisa exemplo: "Metodologia de tomada de dados"; outras poderiam ser sinônimas sem diferença conceitual: "Pesquisa participativa", "pesquisa qualitativa com características de pesquisa participante", ou "pesquisa-ação", "investigação-ação educacional”, "investigação-ação", e assim sucessivamente. A quarta parte (25\%) dos trabalhos não teve denominação explicita e, junto com a pesquisa-ação que mostra uma porcentagem semelhante, somam quase a metade (50\%). Ou seja, o restante das outras denominações soma 50\%, sendo quase um quarto do total de trabalhos analisados correspondente às denominações Pesquisa qualitativa, Estudo de caso, Pesquisa colaborativa, Pesquisa etnográfica, Pesquisa-ação colaborativa e Pesquisa participante. O outro quarto corresponde às denominações em um ou dois trabalhos, e constituído por uma enorme lista. 
Nos trabalhos em estudo, as denominações dos tipos de pesquisa para se ampararem teórica e metodologicamente apresentam citações de autores cujos referenciais teórico-metodológicos são diversos. Entretanto, as denominações são mais o cumprimento de um requisito da formalidade metodológica exigida pela maioria dos investigadores e, em geral, pela academia, do que uma denominação para sintetizar ou enunciar os procedimentos e/ou metodologias de uma pesquisa. Nesse sentido, são poucos os avanços observados na conceituação e construção de novas metodologias e menos ainda na construção de metodologias de pesquisas que visem também à formação de professores.

Levando em conta o binômio pesquisa qualitativa e pesquisa quantitativa observamos que, embora a pesquisa qualitativa seja enunciada com uma baixa porcentagem, $12 \%$, pode estar incluída conceitualmente, e em seus procedimentos, dentre outras denominações de pesquisa aqui enunciadas, tais como colaborativa, participante, coletiva e inclusive a pesquisa-ação que é enunciada, independentemente, com a maior porcentagem de todos os registros nos trabalhos de pesquisa deste estudo.

Nas pesquisas de intervenção são enunciadas, de fato, ações formativas junto a grupos de professores; entretanto, essas ações são, em sua maioria, pontuais; ou seja, não pretendiam ou não conseguiram sua continuidade como processo formativo dos professores, nem como processo de constituição do grupo ou de um coletivo como tal.

Observam-se, ainda, resultados relacionados aos números e procedimentos de ações formativas com intuito de tomar a realidade dos professores para refletir sobre a mesma, tentando sua mudança. Isto é o que, em geral, coloca tais pesquisas como sendo de intervenção. Certamente há uma intencionalidade junto aos 
professores de, com base em sua realidade, refletirem sobre ela e tentar mudanças via estudo ou formação.

Entretanto, observamos metodologias e procedimentos que, mesmo pretendendo e até tentando a intervenção na realidade, continuam arraigadas a modelos tradicionais positivistas, mais interessados com os resultados em termos acadêmicos, isto é, de obtenção de dados para fundamentarem as pesquisas, do que com um compromisso político de construção e constituição de coletivos em e para a transformação da realidade. Existem modelos metodológicos estagnados e estagnantes do desenvolvimento social e da pesquisa que dificultam a construção de conhecimentos para liberação dos poderes de dominação política, econômica e do conhecimento.

A intervenção como metodologia e procedimento de pesquisa nos trabalhos observados se efetiva mediante inúmeras tentativas de conhecer a realidade e produzir mudanças na mesma, aproximando-se dos espaços do exercício docente e escutando os professores para ajudá-los a refletir sobre seus interesses, necessidades, possibilidades etc. Entretanto, essa intervenção, mesmo como tentativa de mudança, pode ser mais um processo de dominação pelo conhecimento (nesse caso, pelos mesmos procedimentos e metodologias de pesquisa), do que um processo de mediação para a construção de autonomia individual e coletiva, entendendo a escola como um coletivo institucional, cujo corpo docente é parte do todo escolar e social. Nesse sentido, se destaca a proposta de pesquisa coletiva que visa à construção e constituição de um coletivo de professores para sua Formação Continuada em Serviço. Caracteriza-se tal proposta, segundo Alvarado Prada (2008, 2010), pela participação do coletivo escolar em seu espaço e tempo de trabalho, por conseguinte, remunerada e tendo seus interesses e necessidades como objeto de pesquisa e conteúdos de formação. 


\section{Referências}

ALBUQUERQUE, A. R.; MELO, R. M. Equivalência de estímulos: conceito, implicações e possibilidades de aplicação. In: RODRIGUES, J. A.; RIBEIRO, M. R. (Orgs.). Análise do comportamento: pesquisa, teoria e aplicação. Porto Alegre: Artmed, 2005.

ALVARADO PRADA, Luis Eduardo. Ações de formação continuada de professores desenvolvidas em municípios da região de Uberaba. Projeto de pesquisa. Uberaba: UNIUBE, $2006 \mathrm{~b}$.

. Formação participativa de docentes em serviço. Tautabé: Cabral Editora Universitária Ltda., 1997.

Investigación colectiva: aproximaciones teórico-metodológicas.

Estúdios Pedagógicos, Valdivia, v. 39, n.1, 2008. Disponível em: $<$ http://www.scielo.cl/scielo.php?script=sci_arttext\&pid=S0718$7052008000100009 \& \operatorname{lng}=\mathrm{pt} \& \mathrm{nrm}=\mathrm{iso}>$.

Pesquisa coletiva como um caminho na formação de professores. Anais do $3^{\circ}$ Encontro de Pesquisas em Educação, Uberaba: UNIUBE, 2005, p. 626-637.

. Pesquisa Coletiva na Formação de Professores. Revista de Educação Pública, Cuiabá, v. 15, n. 28, p. 101-118, maio-ago. 2006a.

; VIEIRA, Vânia Maria de Oliveira; LONGAREZI, Andréa Maturano. Concepções de formação de professores nos trabalhos da ANPED 2003-2007. Anais da 32a Reunião Anual da ANPED. Caxambú: ANPED, 2009. p. 1-17.

ALVARADO-PRADA, Luis Eduardo; FREITAS, T. C.; FREITAS, C. A. Formação Continuada de Professores: Alguns Conceitos, Interesses, Necessidades e Propostas. Revista Diálogo Educacional, v. 10, p. 367387, maio-ago. 2010.

ANDRÉ, Marli. Etnografia da prática escolar. Campinas: Papirus, 1995.

BARBIER, René. A Pesquisa-ação. Brasília, DF: Líber Livro, 2004.

BOGDAN, R. C.; BIKLEN, S. K. Investigação qualitativa em educação. Porto: Porto Editora, 1994. 
BOTERF, Guy Le. Pesquisa participante: propostas e reflexões metodológicas. In: BRANDÃO, Carlos R. (Org.). Pesquisa Participante. São Paulo: Brasiliense, 1987. p. 51-81.

BRANDÃO, Carlos Rodrigues. Pesquisar-participar. In: Pesquisa participante. 8. ed. São Paulo: Brasiliense, 1990. p. 9-16.

CANDAU,V. M. C. Formação continuada de professores: tendências atuais. In: REALI, A. M. M. R.; MIZUKAMI, M. G. N. (Orgs.). Formação de professores: tendências atuais. São Carlos: edUFSCar, 1996.

COLE, A.; KNOWLES, J. G. Teacher Development partnership research: a focus on methods and issues. American Educacional Research Journal, v. 30, 1993.

COLE, Michael; SCRIBNER, Sylvia. Introdução. In: VYGOTSKY, Lev Semynovitch. A formação social da mente. 6. ed. São Paulo: Martins Fontes, 1999. p. 1-19.

DEMO, Pedro. Pesquisa participante: saber pensar e intervir. Brasília: Líber Livro, 2004.

DESGAGNÉ, S. Reflexions sur lê concept de recherche collaborative. Lês Journées du CIRADE. Centre Interdisciplinaire de Recherche sur I'Apprentissage et lê Développementem Éducation, Université du Québec á Montreal, 1998. Tradução de Adir Luiz Ferreira, em nov. 2003.

EZPELETA, J.; ROCKWELL, E. Pesquisa participante. 2. ed. São Paulo: Cortez e Autores Associados, 1989.

FALS BORDA, Orlando. Aspectos teóricos da pesquisa participante: considerações sobre o significado e o papel da ciência na participação popular. In: BRANDÃO, Carlos Rodrigues. Pesquisa participante. 8. ed. São Paulo: Brasiliense, 1990. p. 42-62.

. La ciencia y el pueblo. Nuevas reflexiones sobre la investigaciónacción. In: III CONGRESO NACIONAL DE SOCIOLOGÍA. La sociologia em Colombia. Bogotá: Associación Colombiana de Sociología, 1981. p. 149-174. 
Por la práxis: el problema de como investigar la realidad para transformala. In: (Org.). Crítica y política em ciências sociales. Bogotá: Punta de Lanza, 1978. v. I. p. 209-249.

FIORENTINI, Dario. Pesquisar práticas colaborativas ou pesquisar colaborativamente? In: BORBA, Marcelo Carvalho; ARAÚJO, Jussara de Loiola (Orgs.). Pesquisa qualitativa em Educação Matemática. Belo Horizonte: Autentica. 2004. Cap 2, p. 47-76.

FREIRE, Paulo. Ação cultural para a liberdade. Rio de Janeiro: Paz e Terra, 1978.

. Criando métodos de pesquisa alternativa: aprendendo a fazêla melhor através da ação. In: BRANDÃO, Carlos Rodrigues (Org.). Pesquisa participante. São Paulo: Brasiliense, 1981a. p. 34-41.

Paz e Terra, 2007a.

Educação como prática de liberdade. 31. ed. Rio de Janeiro: . Educação e mudança. 30. ed. Rio de Janeiro: Paz e Terra, 2007c.

. Educação popular e conscientização no meio rural latinoamericano. In: WERTHEIN, J.; BORDENAVE, J. D. Educação Rural no Terceiro Mundo. Rio de Janeiro: Paz e Terra, 1981 b.

. Investigación y metodologia de la investigación del tema generador. In: Cristianismo y Sociedad: Contribución al proceso de concientización en América Latina. Uruguai: ISAL, 1968. p. 27-52. (Suplemento).

2003.

. Pedagogia da autonomia. 28. ed. Rio de Janeiro: Paz e Terra, . Pedagogia do oprimido. 45. ed. Rio de Janeiro: Paz e Terra, 2007b. . Research methods. Literary discussion, p. 133-142, primavera 1974.

GAJARDO, Marcela. Pesquisa participante: propostas e projetos. In: BRANDÃO, Carlos R. (Org.). Pesquisa Participante. São Paulo: Brasiliense, 1987. p. 15-50. 
GARCIA, Ana Maria. A experiência do conhecimento. In: HÜHNE, Leda Miranda (Org.). Metodologia científica. Rio de Janeiro: Agir, 2001.p. 34-41.

GARRIDO, Elsa; MOURA, Manoel Oriosvaldo; PIMENTA, Selma Garrido. A pesquisa colaborativa na escola como abordagem facilitadora para o desenvolvimento da profissão do professor. In: MARIN, Alda Junqueira (Org.). Educação Continuada: reflexões, alternativas. Campinas: Papirus, 2000.

HORRUITINER, P. El trabajo metodológico. Una concepción desde la vicerrectoría académica. La Habana: MES; Dirección de Formación de Profesionales, 1998.

. El trabajo metodológico del departamento docente como un sistema. Revista Cubana de Educación Superior, La Habana, v. 3, n. 1, 1979.

. La universidad cubana: el modelo de formación. La Habana: Editorial Félix Varela, 2006.

IBIAPINA, Ivana Maria Lopes de Melo. Pesquisa Colaborativa: investigação, formação e produção de conhecimentos. Brasília: Líber Livro, 2008.

IMBERNÓN, F. Formação docente e profissionalização. Formar-se para a mudança e a incerteza. 3. ed. São Paulo: Cortez, 2002. 119 p.

KEMMIS, Stephen. Critical Reflection: Staf development for school improvenient. Tradução: Ivana Ibiapina. Philadelphia: Imago Publishing, 1987.

MARCELO GARCÍA, Carlos. Formação de Professores: para uma mudança educativa. Porto: Porto Editora, 1999. p. 17-30.

LEONTIEV. A. N. O desenvolvimento do psiquismo. Lisboa: Horizonte Universitário, 1978.

LONGAREZI, Andréa M.; ARAÚJO, Elaine S.; FERREIRA, Sueli. A psicologia histórico-cultural na formação do profissional docente. Revista Série Estudos. Campo Grande: Editora da UCDB, p. 65-78, jan./jun. 2007. 
LUCARELLI, E. La capacitación docente y la descentralización. Proyeto Multinacional de Educación Básica. Buenos Aires: Organizacións de los Estados Americanos (OEA); Programa Regional de Desarrollo Educativo, 1990.

LUDKE, Menga; ANDRÉ, Marli E. D. A. Pesquisa em educação: abordagens qualitativas. São Paulo: EPU, 1986.

MACEDO, Roberto Sidnei. A etnopesquisa crítica e multirreferêncial nas ciências humanas e na educação. Salvador: EDUFBA, 2000.

MARIN, Alda Junqueira; GUARNIERI, Maria Regina; ROMANATTO, M. C.; CHAKUR, C. R. S. L.; GIOVANNI, L. M.; DIAS DA SILVA, Maria Helena G. F. Desenvolvimento profissional docente e transformações na escola. Pro-Posições (Unicamp), Campinas, v. 11, n. 31, p. 15-24, 2000.

MONT'ALVERNE CHAVES, Iduina; GUEDES, Adrianne. Educar para a sensibilidade: pressupostos teóricos. Rio de Janeiro, 2005. (Mimeografado).

MOURA, Maria da Glória Carvalho; FERREIRA, Adir Luiz. A pesquisa colaborativa e a formação continuada do professor de educação de jovens e adultos: uma reflexão necessária. 2004. Disponível em: <http:// www.ufpi.br/mesteduc/eventos/iiiencontro/gt1/pesquisa_colaborativa. pdf $>$. Acesso em: 18 dez. 2008.

NÓVOA, António. Concepções e práticas da formação contínua de professores. In: (Org.). Formação contínua de professores: realidade e perspectivas. Aveiro: Universidade de Aveiro, 1991.

. Os professores na virada do milênio: do excesso dos discursos à pobreza das práticas. Educação e Pesquisa, São Paulo, v. 25, n. 1, p. 11-20, jan./jun.1999.

PEREIRA, Elisabete Monteiro de A. Professor como Pesquisador: o enfoque da pesquisa-ação na prática docente. In: GERALDI, Corinta M. G.; FIORENTINI, Dario; PEREIRA, Elisabete M de A. (Orgs.). Cartografias do trabalho docente: professor (a)-pesquisador(a). Campinas: Mercado das Letras, 1998. 
PEREIRA, Júlio E. D.; ZEICHNER, Kenneth M. (Orgs.). A pesquisa na formação e no trabalho docente. Belo Horizonte: Autêntica, 2002.

PUENTES, R. V.; AQUINO, O. F. Desafios na profissionalização da docência universitária: entre a privacidade das práticas pedagógicas, a autonomia exagerada e a fragilidade dos mecanismos institucionais. Educação e Filosofia, v. 24, n. 48, p. 273-298, jul./dez. 2010.

REALI, A. M. M. R et al. O desenvolvimento de um modelo "construtivocolaborativo" de formação continuada centrado na escola: relato de uma experiência. Caderno Cedes, Campinas, n. 36, 1995.

RIZZINI, I.; CASTRO, M. R.; SARTOR, C. S. D. Pesquisando: guia de metodologia de pesquisa para programas sociais. Rio de Janeiro: USU; Ed. Universitária, 1999.

SCHÖN, D. A. Educating the reflective practitioner. S. Francisco: Jossey-Bass Publ., 1987.

. Formar professores como profissionais reflexivos. In: NÓVOA, António (Org.). Os professores e sua formação. Lisboa: Dom Quixote, 1992. p. 78-91.

THIOLLENT, Michel. Crítica metodológica, investigação social e enquete operária. São Paulo: Polis, 1987a.

. Metodologia da pesquisa-ação. 8. ed. São Paulo: Cortez, 1998.

. Metodologia da pesquisa-ação. 12. ed. São Paulo: Cortez, 2003.

. Notas para o debate sobre pesquisa-ação. In: BRANDÃO, Carlos Rodrigues (Org.). Repensando a pesquisa participante. São Paulo: Brasiliense, 1987b.

Pesquisa-ação nas organizações. São Paulo: Atlas, 1997. ZEICHNER, K. Formação reflexiva de professores: idéias e práticas. Lisboa: Educa, 1993.

YIN, R. Case study research: design and methods. London: Sage, 1989. 


\section{Notas}

*Apoio: CNPq e Fapemig.

** Professor visitante Sênior CAPES/UNILA - Universidade Federal da Integração Latino-americana. E-mail: <leaprada@hotmail.com>.

${ }^{* * *}$ Professora adjunta, Faculdade de Educação - Universidade Federal da Integração Latino-americana. E-mail: <andrea@faced.ufu.br>. 